Fisheries Research

November 2018, Volume 207 Pages 28-36

\title{
Investigating spatial heterogeneity of von Bertalanffy growth parameters to inform the stock structuration of common sole, Solea solea, in the Eastern English Channel
}

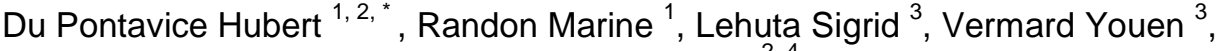 \\ Savina-Rolland Marie ${ }^{2,4}$
}

\author{
${ }^{1}$ Université Bretagne Loire, Agrocampus Ouest, UMR 985 Ecology and Ecosystem Health, CS 84215, \\ 35042, Rennes Cedex, France \\ ${ }_{2}^{2}$ Ifremer, Unité d'Halieutique Manche Mer du Nord, F-62321, Boulogne sur Mer, France \\ ${ }^{3}$ Ifremer, Unité Ecologie et modèles pour l'halieutique, F-44311 Nantes 03, France \\ ${ }^{4}$ Ifremer, Sciences et Technologies Halieutiques, F-56100 Lorient, France \\ * Corresponding author : Hubert Du Pontavice, email address : \\ hubert.dupontavice@agrocampus-ouest.fr
}

\begin{abstract}
:
In fisheries science, a mismatch between the delineation of a fish stock and the underlying biological population can lead to inaccurate assessment and management. Previous results suggested a potential spatial structuration of the Eastern English Channel (EEC) stock of common sole, Solea solea, in three sub-populations. In this article, we propose to investigate the spatial population structure of common sole in the EEC using the von Bertalanffy Growth Function parameters as indicators of population segregation. In order to test the sub-population hypothesis and evaluate its robustness to data sources, we developed three models, all including an area effect on growth parameters. The first model was aimed at testing a potential data source effect (in addition to the area effect) using commercial and scientific survey data jointly. The two other models used either scientific survey or commercial fishery data and focused on spatial differences in growth parameters. Our results showed that the growth parameter estimates indeed differed depending on the type of data used, with higher estimated asymptotic length and length at age two (L2) using commercial data. They also highlighted spatial differences in asymptotic length, consistent between models, which tend to confirm a spatial structuration of sole in the EEC. While these results need to be strengthened by marking and genetic studies, they constitute a first step towards a better understanding of the population spatial structuration of common sole in the EEC.
\end{abstract}




\section{Highlights}

- Von Bertalanffy growth parameters are used to inform the spatial structuration of an exploited species. Spatial differences in asymptotic length reinforce the metapopulation hypothesis. Growth parameters estimates differ depending on the type of data used - scientific survey or commercial fisheries.

Keywords : Key-words, von Bertalanffy growth function, Stock structuration, Solea solea, Flatfish, Lifehistory traits, Metapopulation

\section{Abbreviations}

- VBGF, von Bertalanffy growth function;

- EEC, eastern english channel;

- SW, southwest;

- NE, northeast;

- ICES, International Council for the Exploration of the Sea;

- UK-BTS, UK beam trawl survey;

- NLR, non-linear regression;

- GNLS, generalized nonlinear least squares 


\section{Introduction}

48

49

50

51

52

Harvested species are usually assessed and managed at the stock-unit scale, a stock being defined as an intraspecific group of individuals randomly mating and maintaining its integrity in time and space(Ihssen et al., 1981). Boundaries of these stock units are supposed to reflect the underlying population structures in terms of biological rates such as mortality and growth (Cadrin et al., 2014; Kerr et al., 2016). Recent research suggests that a strong population structuration in marine fish is a relatively common situation (Ames and Lichter, 2013; Ciannelli et al., 2013; Reiss et al., 2009; Waples and Gaggiotti, 2006), and is mainly driven by oceanographic and environmental factors and larval diffusion (Cowen, 2006; Jorgensen et al., 2005), but also by species' specific migratory behaviour (Secor, 2015) and sequential occupancy of various habitats throughout the lifespan (Petitgas et al., 2013, 2010). An assumed single homogeneous population can sometimes turns out to be a set of sub-populations linked by dispersal, i.e., a metapopulation (Alex Smith and Green, 2005; Hanski, 1998; Kritzer and Sale, 2004). Mismatch between the stock-unit delineation and the true metapopulation structure may impede our capacity to provide adequate management recommendations (e.g., Total Allowable Catch) and may lead to overfishing of the less productive sub-populations while the more productive sub-populations are underexploited (Cadrin and Secor, 2009; Frank and Brickman, 2000; Fu and Fanning, 2004; Ricker, 1981). In the past decade, stock identification has been explored for numerous fish stocks, such as blue whiting, Atlantic cod , and horse mackerel (Abaunza et al., 2008; Mahe et al., 2007; Zemeckis et al., 2014) and led to revise stock boundaries.

The Eastern English Channel (EEC) common sole, Solea solea, is a nursery-dependent flatfish species harvested across its entire range, from the Mediterranean to Baltic Sea 
71 (Wheeler, 1978). Reproduction occurs from winter to spring throughout the distribution

72 area, resulting in several weeks of pelagic larval drift before settlement and 73 metamorphosis in coastal and estuarine nursery grounds (Rochette et al., 2012) . After 74 two years, mature common soles are recruited to the stock and can in turn reproduce 75 (Dorel et al., 1991; Riou, 2001). The common sole is a high value targeted fish in the EEC with some fleets highly dependent on it. Fishing mortality on EEC common sole has decreased over the last decade and was estimated below Fmsy - the fishing mortality that produces the maximum sustainable yield (ICES, 2017) - for the first time in 2017 (ICES, 2017) due to a series of low recruitments. However, the biomass is still below the targeted value (MSY Btrigger; ICES, 2017).

Contrasts in the length structure of French landed common sole between the North and South of the EEC raise concerns about a possible misunderstanding of the stock structure (Du Pontavice et al., personal communication). The fleets fishing on the EEC sole are segregated in space, across areas corresponding to potentially different components of the population. It is therefore crucial to improve our knowledge of spatial structuration and population connectivity within the EEC stock and to check whether the hypothesis of a unique stock matches the underlying population structure. A body of research already investigated the level of connectivity of common sole population in the EEC at different stages of the life cycle. First, larval advection to coastal nursery grounds has been shown to limit the connectivity between the different spawning and nursery grounds (Rochette et al., 2012). Second, previous analyses evidenced juveniles common sole as sedentary in their nursery grounds during the two first years of life (Coggan and Dando, 1988; Le Pape and Cognez, 2016). Finally, former mark-recapture surveys suggested low mobility of adult common sole (Burt and Millner, 2008; Kotthaus, 1963). On the basis of these 
results, recent modelling studies hypothesized the existence of three sub-populations spatially structured within the EEC (Figure 1; (Archambault et al., 2016; Rochette et al., 2012). Archambault et al., (2016) assessed the effect of adult-mediated connectivity on population dynamics and stock assessment and concluded that ignoring possible metapopulation could lead to overexploitation of local populations in the EEC. The authors also suggested that research should focus on the adult-mediated connectivity, which remained largely unknown and which magnitude could be a strong driver of spatial structuration within the EEC (Frisk et al., 2014). Recently, the improvement and the multiplication of stock identification tools has made stock delineation increasingly precise (Cadrin et al., 2014; Kerr et al., 2016; Pita et al., 2016). In particular, the use of life-history parameters (e.g., age, growth and mortality) is particularly relevant and cost-efficient (Cadrin et al., 2014). For instance, Barrios et al. (2017) coupled individual growth trajectories and length-at-age datasets in mixed-effects models to investigate stock identification of whiting in the North East Atlantic. Erlandsson et al. (2017) suggested a reconsideration of assessment models of European Flounder based on the spatiotemporal structure of body size in the Baltic Sea. Given the before-mentioned differences in EEC common sole length structure, we propose to study the spatial heterogeneity in length at age as a way to identify spatial structuration within the stock and to test the three common sole sub-populations hypothesis mentioned earlier. Growth is usually modelled using the von Bertalanffy Growth Function (VBGF; Von Bertalanffy, 1938) which provides a non-linear relationship between length and age of organisms. In the present work, we do not aim at describing the growth processes but rather at summarising the characteristics of the length-at-age relationship in delineated subareas in the EEC stock using the three parameters of the VBGF. To avoid bias in the 
119 analysis, length-selection in data collection must be avoided and the spatial and temporal

120 coverage has to be representative of the spatial entity considered. In the EEC, two types

121 of data were available to us: data from a scientific survey (the UK Beam Trawl Survey) and

122 sampling data from French commercial landings. Differences in length-at-age between

123 survey and commercial data can be expected: scientific survey are designed to reflect the

124 length structure of the population, while the length structure of commercial landings is

125 influenced by the minimum landing size imposed by EU on common sole, through fishing

126 strategy (e.g., commercial fisheries tend to fish in areas with the biggest common soles),

127 size-selectivity, and discarding practices.

128 In this study, we investigated the spatial variability in VBGF parameters within the EEC

129 stock of common sole in order to inform current interrogations about population spatial

130 structuration. Based on the three subpopulations hypothesis (Archambault et al., 2016;

131 Rochette et al., 2012), we first evaluated the spatial differences in VBGF parameters

132 accounting for potential bias due to the type of data used (i.e., commercial or survey

133 data). Then, we used the two types of data separately to inform spatial growth

134 differences between the three subareas of the EEC stock of common sole. 


\section{Materials \& methods}

\section{$136 \quad$ 2.1. Data}

137 Biological data for common sole in the EEC were extracted from the French commercial 138 sampling program and onboard sampling during the UK Beam Trawl scientific Survey (UK139 BTS).

\subsubsection{Data from French commercial fisheries}

141 Samples from commercial fisheries were collected in fish markets and provided individual

142 information on age and total length (10mm classes) by quarter, year, ICES division and 143 fishing gear. In order to determine the subarea of origin, the fishing location of each 144 sample had to be identified (Figure 1): Each sampled fish was linked to a statistical 145 rectangle by using logbook information for the corresponding fishing trip. Two main 146 assumptions had to be made for this association: (i) sampled common soles were

147 allocated to the statistical rectangle where the fishing vessel caught the largest volume of 148 common sole during the trip and (ii) in the NE subarea, common soles caught by netters 149 in a statistical rectangle shared by two subareas were assigned to the subarea closest to 150 the shore (for instance in ICES statistical rectangle 30F1 (Figure 1), common soles caught 151 by netters were assigned to the NE subarea). Indeed French netters usually operate in 152 French coastal zones within subareas NE and SW (Figure 1). Biological data from commercial sampling comes from trammel netters in the NE of the EEC and from trammel netters (31\%), bottom trawlers (63\%), and unidentified gears (5\%) in the SW. The French sampling program operates quarterly and individuals are randomly selected in the fish markets using a stratified sampling by sex and length-class. The data used cover the

157 period 2010 to 2015. 
159 The UK-BTS survey has been carried out annually in July/August since 1989 by the Centre 160 for Environment Fisheries and Aquaculture Science (CEFAS), using a commercially rigged $1614 \mathrm{~m}$ steel beam trawl (ICES, 2009). Samples from UK-BTS provided individual information on age and total length with the exact haul position (Figure 1). At each haul, individuals

163 are randomly selected using a stratified sampling by sex and length-class. UK-BTS data are 164 publically available and were extracted from the International Council for the Exploration of the Sea (ICES) database (www.ices.dk/marine-data/) for the period 2010 to 2015.

\subsubsection{Differences between the two data sources}

The two data sources differ by their spatial and temporal coverage, and observed age composition. In both biological data sources, age estimation was conducted by otoliths sagitta reading by IFREMER in France for commercial data and by CEFAS for survey data. Reader effects on otolith reading have been tested in workshops (involving both IFREMER and CEFAS) and agreement between institutes was 91\% for all ages (ICES, 2009). Both

172 data series are available over the period between 2010 and 2015. Survey data are 173 substantial from age 1 (common soles at age 1 represent $21 \%$ of total number of fish) 174 while commercial data become substantial only from age $2(<1 \%$ of age 1 in the third 175 quarter). This is likely due to the minimum landing size of $24 \mathrm{~cm}$ in place for sole 176 (Supplementary material S1).

\section{2.2. Model formulation}

178 Differences in length at age were investigated through analyses of the VBGF parameters. 179 As in Rindorf et al. (2016), cohort effects were ignored considering the short period of 180 observations in comparison with common sole life span. Year effects, usually included as 181 proxies for annual environmental conditions, were also neglected because the purpose 

between subareas and data sources. The growth equation was parameterized from age 2 ,

$$
L_{t, i}=L_{\infty}-\left(L_{\infty}-L_{2}\right) \times \exp \left(-K \times\left(t_{i}-2\right)\right)+\varepsilon_{i}
$$

184

where $\varepsilon_{i}$ is a normally distributed error term.

$L_{t, i}$ is the length of the individual $i$ at age $t, L_{2}$ the length at age $2, L_{\infty}$ the asymptotic maximum length, and $\mathrm{K}\left(\mathrm{year}^{-1}\right)$ is the intrinsic somatic length growth rate (i.e., the speed at which the asymptotic length is reached).

To identify the influence of subareas and data sources on the estimates of the growth parameters, a generalized nonlinear least squares (GNLS) model was used. This model was formulated using a two-stage framework (Pinheiro and Bates, 2000).

First, the length of the i-th common sole is modelled by Eq. 1.

Second, covariates were introduced in the model. The covariates tested included (i) the three subareas (denoted "subarea"), (ii) the two data sources (denoted "data"), (iii) the sexual dimorphism (denoted "sex"), and (iv) the annual growth continuity (denoted "quarter"). The three growth parameters can be expressed as a vector: $\phi j=\left[K, L_{\infty}, L_{2}\right]$ with $\phi=A . \beta . A$ is the designed matrix whose size depends on the number of covariates and the number of groups in each covariate, and $\beta$ is the vector of parameters for the covariates. For example, in a model considering the three subareas in the EEC (NE, SW, and UK) and the sexual dimorphism (Male or Female) (i.e., Model 2), $K, L_{\infty}$, and $L_{2}$ can be expressed as: $\left\{K=\beta_{1}+\beta_{2}\right.$.SubareaSW $+\beta_{1}$.SubareaUK $+\beta_{4}$.SexMale $\},\left\{L_{\infty}=\beta_{5}+\beta_{6}\right.$.SubareaSW + $\beta_{7}$.SubareaUK $+\beta_{8}$.SexMale $\},\left\{L_{2}=\beta_{9}+\beta_{10}\right.$.SubareaSW $+\beta_{11}$.SubareaUK $+\beta_{12}$.SexMale $\}$.

Subarea and data were the covariates of interest: subarea captures potential variations in length-at-age between subareas in the EEC and data documents the potential differences in the perception of length-at-age relationships between commercial and survey data. 
Both sex and quarter effects were used to avoid bias in estimation. Indeed, sexual

206

207

208

209

210

211

212

213

dimorphism was described for common sole by several authors (De Veen, 1976; Rijnsdorp and Van Beek, 1991). Moreover, the fishing strategy (fishing area and period) of commercial fisheries leads to a high share of female in the capture $(81 \%)$ compared to the scientific survey (45\%). The quarter effect aimed at capturing the variability caused by the annual growth continuity and reducing the incidence of unbalanced sampling in the commercial fisheries. Indeed, in the NE of the EEC common sole are sampled homogeneously throughout the year, while, in the SW, $83 \%$ of common sole are sampled in the $2^{\text {nd }}$ and the $3^{\text {rd }}$ quarter.

This general form was then applied in three alternative models which differed by the datasets and the covariates considered (Summarised in Table 1).

Table 1: Summary of the three models implemented to analyse the effects of sex, subarea, quarter, and data source on growth parameters $K, L_{\infty}$ and $L 2$, across the three subareas $N E$, SW and UK. For each model, the ticks represent the inclusion (or not) of effects tested on each growth. The green boxes are the effects selected by the models. $Q$ stands for Quarter.

\subsection{Model description}

2.3.1. Model 1: commercial and survey data

The first model (Model 1) was aimed at verifying if commercial and scientific data may be jointly used in estimation or if a data-source bias exists. To allow comparison between the two data sources, we only considered commercial data collected during quarter 3 (because the scientific survey is carried out in July and August), and survey data from NE and SW subareas due to the absence of catch by French commercial fisheries in the UK 
subarea. The model was fitted on a resulting dataset of 3,113 length-age couples from survey (45\%), and commercial fishery (55\%).

232 The effect of sex $\left(\beta_{1}\right)$, subarea $\left(\beta_{2}\right)$, data source $\left(\beta_{3}\right)$ and the interaction between subareas and data source $\left(\beta_{4}\right)$ were included in the model. Consequently, the model produces independent estimations for each combination of data source and subarea.

2.3.2. Model 2 and 3: independent analysis of commercial and survey data: subarea effect on the estimates of growth parameters

Model 2: Survey data

The second model was fitted to survey data only and aimed at detecting potential differences in length at age between the three subareas, independent from bias due to different fishing practices across regions (e.g., differences in mesh size, targeting of sizes and discards). The non-linear model tested the effects of subarea $\left(\beta_{1}\right)$ and sex $\left(\beta_{2}\right)$.

242 We considered 2,863 individuals of age 1 to age 23 from UK-BTS for the 3 subareas: NE $243(33 \%)$, SW (16\%) and UK (50\%) (the age structure in the dataset is described in 244 Supplementary material S2). We noted that the quantity of data in the SW subarea is 245 relatively low in comparison with the NE and UK subareas.

Model 3: Commercial data

247 Model 3 was fitted to data from commercial fisheries and tested the effects of subarea

$248\left(\beta_{2}\right)$, season $\left(\beta_{3}\right)$ and sex $\left(\beta_{1}\right)$. As for model 1 , data were available only in the two subareas 249 fished by the French commercial fleets (i.e., NE and SW subareas). Commercial data are sampled throughout the year, thus a quarter effect was added in order to consider the 251 annual growth continuity.

252 The interest of this model lies in the quantity of available data $(5,391$ individuals of age 1 253 to age 24) particularly in the SW subarea wherein the quantity of data was low in the 
scientific survey in comparison with the NE and the UK subareas (Supplementary material S3 and S4). We considered a quarter effect on $\mathrm{K}$, because the speed of growth may depend on environmental seasonal conditions. Inversely we did not consider a quarter effect on the asymptotic length, which is viewed as the maximum length reached by the population and reflects the cumulative growth history of fish thus constant throughout the year at population scale.

\subsection{Model selection}

The three models were implemented in the statistical software R (R Core Team, 2016) using the 'gnls' function (package 'nlme'; (Pinheiro and Bates, 2000). Backward stepwise procedure was performed and the Akaike Information Criterion (AIC) and the Bayesian Information Criterion (BIC) were used to select the best model. The initial model was the full model (all covariate effects on all three parameters) and the impact on the criteria of the sequential deletion of each covariate on each parameter was assessed. The covariates whose deletion either improved the model (by reducing $\mathrm{AIC}$ and $\mathrm{BIC}$ ) or did not deteriorate its quality (not significant difference in $\mathrm{AIC}$ and $\mathrm{BIC}$ ) were eliminated. The process was repeated until no further improvement was possible. The significance of the parameters was assessed using a Wald chi-square test. Graphical methods (e.g., residual

271 diagnostic plots) were used to check that the final models verified the normality assumption (Supplementary material S12).

Finally, in order to evaluate the robustness of the conclusions to the shape of the growth curve, we estimated a logistic growth model as an alternative to the VBG model using the UK-BTS data in the SW of the English EEC and the effects selected in Model 2 (Described

276 in the following section; Supplementary material S13). Models were compared using AIC 277 and BIC. 


\section{Results}

279

280

281

282

283

284

285

286

287

288

289

290

291

292

293

294

295

296

297

298

299

300

\subsection{Data source effect on growth parameters}

Model 1 was based on commercial fisheries and survey data in the two subareas NE and SW of the EEC and considered the effects of sex, subarea, data and interaction subarea $x$ data on growth parameters. It revealed a data source effect on $K$ and $L_{2}$ with different magnitude depending on the subarea globally higher in the NE than in the SW.. It also suggested differences in growth between subareas.

The model considering the four effects on the three growth parameters $\left(K, L_{\infty}\right.$ and $\left.L_{2}\right)$ was always selected based on the AIC selection criteria (Supplementary material S6 and S7). In the case of the more conservative BIC criteria, the gain obtained by considering the effect on the growth parameter was $\mathrm{K}$ quite low $\left(\Delta \mathrm{BIC} \mathrm{C}_{\mathrm{S} 1-\mathrm{SO}}=1.07\right.$ and $\left.\Delta \mathrm{BIC}_{\mathrm{S4}-\mathrm{s0}}=0.4\right)$. Consequently, we kept the full model keeping in mind that the four effects on $\mathrm{K}$ might be unclear.

Wald chi-square test indicated that all the parameters were significant with a $p$-value $<$ 0.001 , except for the parameter $L_{\infty}$ associated to the commercial data in the SW subarea $(p$-value $=0.055)$

The sex effect on the three growth parameters was significant and of similar amplitude as the three other effects (Supplementary material S6 and Table 2).

Interaction effect in Model 1 allowed to provide independent estimates for each data source in each subarea. The results showed that differences depending on the data sources in $L_{\infty}, L_{2}$ and $K$. $L_{\infty}$ was $14.5 \%(46.5 \mathrm{~mm})$ higher using commercial data than using UK-BTS in NE, and $5.5 \%(19 \mathrm{~mm})$ in the $\mathrm{SW} . \mathrm{L}_{2}$ was $14.5 \%(32.5 \mathrm{~mm})$ higher using commercial data than using UK-BTS in NE and 9\% $(20 \mathrm{~mm})$ in SW. K was $33 \%$ lower using 

commercial data.

303 The asymptotic length and the length at age 2 were significantly higher using the commercial data compared to the UK-BTS data in the SW and the NE of the EEC, while K were significantly lower using commercial data in the NE and higher in the SW.

Table 2 : Growth parameters of the von Bertalanffy equation computed from the model fitted to data from the scientific survey UK-BTS and commercial sampling, considering data source effect and sex effect. The columns '\% variation' specifies the percentage of variation in each subarea between the data from commercial fisheries and the data from UK-BTS.

The results also showed differences in growth parameters between the two subareas with the two data sources (Figure 2 ), which were consistent across data source for $L_{\infty}$, i.e., higher $L_{\infty}$ in the SW of the EEC.

In the following part, the subarea effect was analysed in details separating data from scientific survey and from commercial fisheries.

\section{$318 \quad$ 3.2. Variations in growth parameters across subareas in the EEC}

3.2.1. Scientific survey UK-BTS data within the three subareas in the EEC

In Model 2, which considered the subarea and sex effects using scientific survey data, the complete model considering all effects on all parameters was selected based on the AIC selection criteria (Supplementary material S8 and S9). On the basis of the BIC criterion, the sub-model S4 would be selected (which releases the subarea effect on K). Even if AIC and $\mathrm{BIC}$ criteria did not provide the same message on the model selection, we chose to keep the subarea effect on $\mathrm{K}$ to be able to look at the potential subarea effect. Wald chisquare test indicated that all the parameters were significant with a $p$-value $<0.001$. 
In this model, sexual dimorphism had a larger effect on the three growth parameters than and Table 3).

The asymptotic length, $L_{\infty}$, showed the largest variation across the three subareas. $L_{\infty}$ was much higher in the SW than in the NE of the EEC ( $+10 \%$ for males and $+9 \%$ for females) and in the UK ( $+7 \%$ for males and $+6 \%$ females) (Table 3$)$. The same result was observed, to a lesser extent, for $L_{2}(+4 \%$ and $+5 \%$ between the NE and $S W$ subareas and $+2 \%$ between the UK and SW subareas). The subarea effect on $\mathrm{K}$ followed a different pattern with $\mathrm{K}$ around 0.40 for males (and 0.31 for females) in the SW and NE subareas whereas it reached 0.46 for males (and 0.37 for females) in the UK subarea.

Both $L_{\infty}$ and $L_{2}$ were higher in the SW of the EEC than in the UK and the same parameters were higher in the UK than in the NE. This means that the differences in terms of lengthat-age exist from youngest age and spread throughout the life cycle of the common sole.

Table 3 : Growth parameters of von Bertalanffy equation computed from the model fitted on data from French commercial fisheries considering subarea effect and sex effect. The columns '\% variation' indicates the percentage of variation between the subareas with the SW subarea as the reference.

\subsubsection{Commercial fisheries data within the two subareas in the EEC}

Model 3 is based on commercial fisheries data with three effects (subarea, quarter and sex) on the three growth parameters. Unlike the two previous models, the fit of this model required four steps and led to the removal of the subarea effect on $\mathrm{K}$ and $\mathrm{L}_{2}$ and the sex effect on K, based on both AIC and BIC (Supplementary material S10 and S11). The 0.001. 
353 The subarea effect and the sex effect were retained for $L_{\infty}$. This parameter was

354 significantly higher in the SW than in the NE subarea $(+14 \%$ for male and $+11 \%$ for

355 female) (Table 4). This was consistent with the results obtained with the survey data. $\mathrm{K}$

356 showed quarterly variation with higher values for the quarters 2 and 3 that were not

357 consistent with intra-annual growth. Finally, sexual dimorphism induced variations in $\mathrm{L}_{\infty}$

358 and $\mathrm{L}_{2}$ but not in $\mathrm{K}$.

359

360 Table 4: Growth parameters of von Bertalanffy equation computed from the model fitted 361 on data from French commercial fisheries considering subarea effect, sex effect and 362 quarter effect.

364 The results showed significant differences across subareas in asymptotic length, $L_{\infty}$, in all 365 models, and differences in length at age $2\left(L_{2}\right)$ with the scientific survey data (Model 1 and

366 Model 2) (Table 1 in green). Asymptotic length was systematically higher in the SW of the

367 EEC than in the NE. Same results were found to a lesser extent for length at Age $2\left(L_{2}\right)$

368 which was higher in the SW of the EEC than in the NE. The growth rate (K) showed small

369 variations between the SW and the NE. The UK subarea was explored only with the data

370 from scientific survey in the Model 2. Nevertheless, the results indicated that $\mathrm{K}$ was much

371 higher in the UK subareas than in the two other subareas, whereas the value of $L_{\infty}$ was

372 intermediate between those in the SW and in the NE subareas. 


\section{Discussion}

374 The use of life-history traits, especially growth parameters, is a well-known method to

375 inform stock identity (Abaunza et al., 2008; Barrios et al., 2017; Cadrin et al., 2014;

376 Sequeira et al., 2012). Herein, we investigated the stock spatial structuration of common

377 sole in the EEC using VBGF to estimate growth parameters, according to an existing three

378 sub-populations hypothesis (Archambault et al., 2016; Rochette et al., 2012). From a

379 methodological perspective, we compared growth parameter estimates using length-at-

380 age data from a scientific survey and a commercial fisheries sampling program. While the

381 estimation of VBGF parameters, $K$ and $L_{\infty}$, for common sole was not the primary aim of

382 the study, the parameters obtained are in the range (or slightly lower for $L_{\infty}$; Deniel,

383 1990; Lorenzen and Enberg, 2002) of those estimated for the same species in surrounding

384 regions (Carpentier et al., 2009; De Veen, 1976; Deniel, 1990; Lorenzen and Enberg, 385 2002).

$386 \quad$ 4.1. Effects of the data source on the growth parameter estimates

387 Different fishing practices provided different perceptions of length-at-age population

388 structure

389 Model 1 was developed to test a potential data source effect on the growth parameter 390 estimates. We found that the three growth parameters estimates were indeed strongly 391 influenced by the data source used in the VBGF model. More precisely, in the two 392 subareas considered in Model 1 (i.e., the SW and NE subareas), $L_{\infty}$ and $L_{2}$ estimates were 393 higher using commercial data compared to survey, particularly in the NE subarea.

394 This data source effect can be attributed to size-selectivity differences between the 395 commercial and scientific fishing practices. The smallest common soles at age 2 (and 396 notably the males, which are smaller) are not captured or not landed by commercial 
397 fisheries, while the scientific survey catches common soles from age 1. Commercial fleets 398 are much more size-selective than scientific survey due to a minimum landing size $(24 \mathrm{~cm})$ 399 imposed by the European Union regulation, and the low commercial value of the smallest 400 commercial category of common sole. This selectivity is induced by gear characteristics 401 (such as mesh size) and by the targeting behaviour. Commercial fisheries tend to fish in areas with the biggest common soles, while scientific survey aims at sampling the entire population using a stratified random design. The perception of the population structure is consequently dependent of the type of data used. Differences in the magnitude of the data source effect between the NE and the SW of the EEC were presented and they may be due to differences in the fishing gears used by the commercial fishery in these two subareas. In the NE, the fishery is mainly composed of trammel nets with smaller mesh

408 size whereas, in the SW, it is composed of trammel nets with bigger mesh size, and 409 bottom trawls.

410 Ones should be careful when combining length-at-age data from various data sources and especially commercial and survey data to build models. Ignoring data source can lead to

412 skew the perception of length-at-age population structure.

413 Methodological limitations: significance of the estimates and correlation between von

\section{Bertalanffy Growth parameters}

415 In the paper, we used the well-known VBGF as a way to summarise the length-at-age in 416 the population. A logistic growth model was also tested and suggested significant 417 differences between subareas as well. However, the best fits were obtained using VBG model (Supplementary materials S13).

419 We included a season effect in the model applied to commercial data as a covariate 420 instead of using decimal ages to account for continuous growth. Indeed, as evidenced by 
421 the estimates of the quarter effect, intra-annual continuous growth was not supported by

422 the data (Supplementary materials S14). This surprising result will lead to further analysis

423 in the future. Meanwhile, accounting for the quarter effect avoids propagating the bias in

424 VBGF estimates.

425 It is important to highlight the correlation between the growth rate (K) and the 426 asymptotic length $\left(L_{\infty}\right)$. In Model 1 , in the NE subarea, $K$ estimate was lower with

427 commercial data compared to survey data whereas the two other growth parameters $L_{\infty}$ 428 and $L_{2}$ were higher with commercial data. In the same way, in Model 2 and $3, K$ was found 429 to vary oppositely to $L_{\infty}$. Correlation matrix of the estimates of Model 1 and Model 2 430 showed a relatively high degree of correlations between in $\mathrm{K}$ and $\mathrm{L}_{\infty}$ estimates (between 4310.87 and -0.81 for the same effect in both models; (Supplementary materials S15 and 432 S16). This correlation between growth parameters may be an artefact of the models' 433 parametrization (Schnute, 1981). However, it may also result from an interaction 434 between two biological processes, growth and maturation especially between $\mathrm{K}$ and $\mathrm{L}_{\infty}$ 435 (Brunel et al., 2013; Lester et al., 2004; Quince et al., 2008).

436 4.2. A first insight into the stock structuration of common sole in the EEC

437 Spatial differences in the asymptotic length $\left(L_{\infty}\right)$, in length-at-age $2\left(L_{2}\right)$ and in growth rate $438 \quad(K)$

439 The second and third models integrated length-at-age data from a scientific survey 440 (Model 2) and commercial fisheries (Model 3), respectively. Both models highlighted that asymptotic length was significantly higher in the SW than in the NE subareas, with the 442 same magnitude between models. Model 2 showed that the length-at-age 2 were also 443 higher in the SW than in the UK subarea. This shows that differences in terms of length444 at-age exist from the youngest age and spread throughout the life cycle of the common 
sole. Furthermore, model 2 highlighted that the growth rate $(K)$ was much higher in the

446 UK subarea compared to the NE and the SW of the EEC. However, we could not confirm

447 these results using the French commercial data. Genetic (intrinsic) and environmental

448 (extrinsic) components are likely to be explicative factors of such differences (Swain et al.,

449 2007). Among extrinsic components, water temperature and density-dependent factors

450 are particularly cited in the literature (e.g., Brett et al., 1969; Brett, 1979; Weatherley,

451 1990; Rijnsdorp and Van Beek, 1991; Sinclair et al., 2002; Castillo-Jordán et al., 2010).

452 Mollet et al. (2013) showed latitudinal variations in asymptotic length of female Solea

453 solea linked to the temperature in the Northern Atlantic. In our case, further research is

454 needed to understand if growth differences in the EEC could be explained by abiotic or

455 biotic factors.

456 Spatial differences in growth parameters support the hypothesis of low mobility of

457 common soles in the EEC. While the movements of common soles at early stages are

458 partially understood in the EEC (Archambault et al., 2015, 2016; Rochette et al., 2012),

459 the mobility of adults remains poorly resolved, but preliminary reprocessing of former

460 mark-recapture surveys data (Burt and Millner, 2008; Kotthaus, 1963) suggested little

461 exchanges between the three subareas (Véron and Rivot, pers. comm). Additional mark-

462 recapture data are currently collected to further support this conclusion.

463 A differential fishing impact within the EEC?

464 Given the strong fishing pressure on common sole in the EEC, these differences in the 465 estimated growth parameters between subareas may be induced, at least partly, by 466 heterogeneous fishing pressure on common sole across areas.

467 One of the first and direct effect of size-selective fishing is to reduce the share of larger 468 individuals in the population, which can lead to a genetic change toward smaller 
469 individuals (Law, 2000; Ricker, 1981). The low asymptotic length in the NE in the EEC

470 could therefore be due to a higher fishing pressure in this subarea compared to the SW

471 and the UK.

472 More generally, fish growth can be subject to a high degree of genetically-based

473 variations and therefore has the potential to evolve rapidly in response to harvesting

474 (Law, 2000; Lorenzen, 2016). Evolutionary effects of fishing on growth may arise from

475 multiple mechanisms including size selective fishing (Enberg et al., 2012). Fishing induced

476 evolution can lead to a decrease of asymptotic length, as shown by Edeline et al., (2009

477 and 2007) in Esox Lucius. The lower growth rate and asymptotic length in the NE of the

478 EEC where the fishing effort is the highest seems to follow this pattern. This is in line with

479 (Archambault et al., 2016) who, under the hypothesis of the existence of distinct sub-

480 populations, estimated a higher fishing mortality in the NE than in the UK since 2000, with

481 the lowest fishing mortality in the EEC in the SW since 1985.

482 The analysis presented herein was conducted on a short and recent period (2010-2015).

483 To explore the hypothesis of differential fishing impact on the potential of common sole

484 in the EEC, it would be necessary to study the size-at-age data throughout a longer time-

485 series in the three subareas (using UK-BTS survey data from 1989 to 2016 for instance).

486 Finally, our analysis was a first step towards the investigation and the understanding of

487 the potential spatial stock structuration of common sole in the EEC. Spatial differences in

488 the asymptotic length appeared consistent between the models, whatever the type of

489 data used. Moreover, the analysis of the survey showed spatial differences in growth rate

490 and length at age 2 in Model 1 and Model 2. These results were in favour of a potential

491 spatial stock structuration following a three subpopulations hypothesis. The confirmation

492 of the existence of three isolated subareas could have major implications on our 
493 perception of the stock and consequently for management. Currently, both stock 494 assessment and management assume a single and homogeneous population and until 495 2016, the EEC stock has been exploited above MSY (ICES, 2016). Accounting for 496 metapopulation dynamics is essential in assessment models to avoid local over497 exploitation (Archambault et al., 2016; Tuck and Possingham, 1994; Ying et al., 2011). To 498 inform this potential metapopulation structure, complementary studies are required 499 (using genetics, otoliths or other life history traits) and would deserve to be integrated in 500 an interdisciplinary approach which is considered to be the best approach to investigate 501 stock identity (Begg and Waldman, 1999; Cadrin et al., 2014; Pita et al., 2016). 
502 Supplementary data

503 Supplementary materials are available at the online version of the manuscript. 


\section{Acknowledgment}

505 We authors are grateful to Bruno Ernande (Ifremer Boulogne-sur-Mer), who provided 506 help and advice on statistical methods. This study was funded by the research program 507 SMAC (France Filière Pêche, DPMA, IFREMER, Agrocampus Ouest, région Hauts-de-France 508 and région Normandie). Publically available data from the UK-BTS survey operated by 509 CEFAS were used in this study. French commercial data were made available by Ifremer 510 SIH - Système d'informations Halieutiques. 
512 Abaunza, P., Murta, A.G., Campbell, N., Cimmaruta, R., Comesaña, A.S., Dahle, G., García

513

514

515

516

517

518

519

520

521

522

523

524

525

526

527

528

529

530

531

532 Santamaría, M.T., Gordo, L.S., Iversen, S.A., MacKenzie, K., Magoulas, A., Mattiucci, S., Molloy, J., Nascetti, G., Pinto, A.L., Quinta, R., Ramos, P., Sanjuan, A., Santos, A.T., Stransky, C., Zimmermann, C., 2008. Stock identity of horse mackerel (Trachurus trachurus) in the Northeast Atlantic and Mediterranean Sea: Integrating the results from different stock identification approaches. Fish. Res. 89, 196-209. https://doi.org/10.1016/j.fishres.2007.09.022

Alex Smith, M., Green, D.M., 2005. Dispersal and the metapopulation paradigm in amphibian ecology and conservation: are all amphibian populations metapopulations? Ecography 28, 110-128. https://doi.org/10.1111/j.09067590.2005.04042.x

Ames, E.P., Lichter, J., 2013. Gadids and Alewives: Structure within complexity in the Gulf of Maine. Fish. Res. 141, 70-78. https://doi.org/10.1016/j.fishres.2012.09.011

Archambault, B., Le Pape, O., Baulier, L., Vermard, Y., Véron, M., Rivot, E., 2016. Adultmediated connectivity affects inferences on population dynamics and stock assessment of nursery-dependent fish populations. Fish. Res. 181, 198-213. https://doi.org/10.1016/j.fishres.2016.03.023

Archambault, B., Rivot, E., Savina, M., Le Pape, O., 2015. Using a spatially structured life cycle model to assess the influence of multiple stressors on an exploited coastalnursery-dependent population. Estuar. Coast. Shelf Sci. https://doi.org/10.1016/j.ecss.2015.12.009 
Barrios, A., Ernande, B., Mahé, K., Trenkel, V., Rochet, M.-J., 2017. Utility of mixed effects models to inform the stock structure of whiting in the Northeast Atlantic Ocean. Fish. Res. 190, 132-139. https://doi.org/10.1016/j.fishres.2017.02.005

Begg, G.A., Waldman, J.R., 1999. An holistic approach to fish stock identification. Fish. Res. 43, 35-44. https://doi.org/10.1016/S0165-7836(99)00065-X

Brett, J.R., 1979. Environmental Factors and Growth, in: Fish Physiology. Elsevier, pp. 599-675. https://doi.org/10.1016/S1546-5098(08)60033-3

Brett, J.R., Shelbourn, J.E., Shoop, C.T., 1969. Growth Rate and Body Composition of Fingerling Sockeye Salmon, Oncorhynchus nerka, in relation to Temperature and Ration Size. J. Fish. Res. Board Can. 26, 2363-2394. https://doi.org/10.1139/f69230

Brunel, T., Ernande, B., Mollet, F.M., Rijnsdorp, A.D., 2013. Estimating age at maturation and energy-based life-history traits from individual growth trajectories with nonlinear mixed-effects models. Oecologia 172, 631-643. https://doi.org/10.1007/s00442-012-2527-1

Burt, G.J., Millner, R.S., 2008. Movements of sole in the southern North Sea and eastern English Channel from tagging studies (1955-2004) (No. 144). Cefas Lowestoft.

Cadrin, S.X., Kerr, L., Mariani, S. (Eds.), 2014. Stock identification methods: applications in fishery science, Second edition. ed. Academic Press, Amsterdam.

Cadrin, S.X., Secor, D.H., 2009. Accounting for Spatial Population Structure in Stock Assessment: Past, Present, and Future, in: Beamish, R.J., Rothschild, B.J. (Eds.), The Future of Fisheries Science in North America. Springer Netherlands, Dordrecht, pp. 405-426. https://doi.org/10.1007/978-1-4020-9210-7_22 
556 Carpentier, A., Martin, C., Vaz, S., 2009. Channel Habitat Atlas for marine Resource

557

558

559

560

561

562

563

564

565

566

567

568

569

570

571

572

573

574

575

576

577

578

579 Management, final report (CHARM phase II). INTERREG 3a Programme, IFREMER, Boulogne-sur-mer, France.

Castillo-Jordán, C., Cubillos, L.A., Navarro, E., 2010. Inter-cohort growth rate changes of common sardine (Strangomera bentincki) and their relationship with environmental conditions off central southern Chile. Fish. Res. 105, 228-236. https://doi.org/10.1016/j.fishres.2010.05.012

Ciannelli, L., Fisher, J., Skern-Mauritzen, M., Hunsicker, M., Hidalgo, M., Frank, K., Bailey, K., 2013. Theory, consequences and evidence of eroding population spatial structure in harvested marine fishes: a review. Mar. Ecol. Prog. Ser. 480, 227-243. https://doi.org/10.3354/meps10067

Coggan, R.A., Dando, P.R., 1988. Movements of juvenile Dover sole, Solea solea (L.), in the Tamar Estuary, South-western England. J. Fish Biol. 33, 177-184. https://doi.org/10.1111/j.1095-8649.1988.tb05571.x

Cowen, R.K., 2006. Scaling of Connectivity in Marine Populations. Science 311, 522-527. https://doi.org/10.1126/science.1122039

De Veen, J.F., 1976. On changes in some biological parameters in the North Sea sole (Solea solea L.). J. Cons. 37, 60-90. https://doi.org/10.1093/icesjms/37.1.60

Deniel, C., 1990. Comparative study of growth of flatfishes on the west coast of Brittany. J. Fish Biol. 37, 149-166. https://doi.org/10.1111/j.1095-8649.1990.tb05936.x

Dorel, D., Koutsikopoulos, C., Desaunay, Y., Marchand, J., 1991. Seasonal distribution of young sole (Solea solea (L.)) in the nursery ground of the Bay of Vilaine (Northern Bay of Biscay). Neth. J. Sea Res. 27, 297-306. https://doi.org/10.1016/00777579(91)90032-V 
Edeline, E., Carlson, S.M., Stige, L.C., Winfield, I.J., Fletcher, J.M., James, J.B., Haugen, T.O., Vøllestad, L.A., Stenseth, N.C., 2007. Trait changes in a harvested population are driven by a dynamic tug-of-war between natural and harvest selection. Proc. Natl. Acad. Sci. 104, 15799-15804. https://doi.org/10.1073/pnas.0705908104

Edeline, E., Le Rouzic, A., Winfield, I.J., Fletcher, J.M., James, J.B., Stenseth, N.C., Vollestad, L.A., 2009. Harvest-induced disruptive selection increases variance in fitness-related traits. Proc. R. Soc. B Biol. Sci. 276, 4163-4171. https://doi.org/10.1098/rspb.2009.1106

Enberg, K., Jørgensen, C., Dunlop, E.S., Varpe, Ø., Boukal, D.S., Baulier, L., Eliassen, S., Heino, M., 2012. Fishing-induced evolution of growth: concepts, mechanisms and the empirical evidence: Fishing-induced evolution of growth. Mar. Ecol. 33, 1-25. https://doi.org/10.1111/j.1439-0485.2011.00460.x

Erlandsson, J., Östman, Ö., Florin, A.-B., Pekcan-Hekim, Z., 2017. Spatial structure of body size of European flounder ( Platichthys flesus L.) in the Baltic Sea. Fish. Res. 189, 19. https://doi.org/10.1016/j.fishres.2017.01.001

Frank, K.T., Brickman, D., 2000. Allee effects and compensatory population dynamics within a stock complex. Can. J. Fish. Aquat. Sci. 57, 513-517. https://doi.org/10.1139/f00-024

Frisk, M.G., Jordaan, A., Miller, T.J., 2014. Moving beyond the current paradigm in marine population connectivity: are adults the missing link? Fish Fish. 15, 242-254. https://doi.org/10.1111/faf.12014

Fu, C., Fanning, L.P., 2004. Spatial Considerations in the Management of Atlantic Cod off Nova Scotia, Canada. North Am. J. Fish. Manag. 24, 775-784. https://doi.org/10.1577/M03-134.1 

https://doi.org/10.1038/23876

606

ICES, 2017. WGNSSK. Report of the Working Group on Assessment of Demersal Stocks in the North Sea and Skagerrak (WGNSSK), 26 April - 5 May 2017, ICES Headquarters, Copenhagen. ICES CM 2017/ACOM:21: 1091pp.

ICES, 2016. Solea (Solea solea) in Division VIId (Eastern English Channel).

ICES, 2009. Manual for the Offshore Beam Trawl Surveys. Revision 1.2., Working Group on Beam Trawl Surveys.

Ihssen, P.E., Booke, H.E., Casselman, J.M., McGlade, J.M., Payne, N.R., Utter, F.M., 1981. Stock Identification: Materials and Methods. Can. J. Fish. Aquat. Sci. 38, 18381855. https://doi.org/10.1139/f81-230

Jorgensen, H.B.H., Hansen, M.M., Bekkevold, D., Ruzzante, D.E., Loeschcke, V., 2005. Marine landscapes and population genetic structure of herring (Clupea harengus L.) in the Baltic Sea. Mol. Ecol. 14, 3219-3234. https://doi.org/10.1111/j.1365$294 X .2005 .02658 . x$

Kerr, L.A., Hintzen, N.T., Cadrin, S.X., Clausen, L.W., Dickey-Collas, M., Goethel, D.R., Hatfield, E.M.C., Kritzer, J.P., Nash, R.D.M., 2016. Lessons learned from practical approaches to reconcile mismatches between biological population structure and stock units of marine fish. ICES J. Mar. Sci. J. Cons. fsw188. https://doi.org/10.1093/icesjms/fsw188

Kotthaus, A., 1963. Tagging experiments with the North Sea sole (Solea solea) in 1959 and 1960. Spec. Publ. Int. Commn. NW. Atlan. Fish 123-129. 
626 Kritzer, J.P., Sale, P.F., 2004. Metapopulation ecology in the sea: from Levins' model to

627

628

629

630

631

632

633

634

635

636

637

638

639

640

641

642

643

644

645

646

647

648 marine ecology and fisheries science. Fish Fish. 5, 131-140. https://doi.org/10.1111/j.1467-2979.2004.00131.x

Law, R., 2000. Fishing, selection, and phenotypic evolution. ICES J. Mar. Sci. 57, 659-668. https://doi.org/10.1006/jmsc.2000.0731

Le Pape, O., Cognez, N., 2016. The range of juvenile movements of estuarine and coastal nursery dependent flatfishes: estimation from a meta-analytical approach. J. Sea Res. 107, 43-55. https://doi.org/10.1016/j.seares.2015.06.001

Lester, N.P., Shuter, B.J., Abrams, P.A., 2004. Interpreting the von Bertalanffy model of somatic growth in fishes: the cost of reproduction. Proc. R. Soc. B Biol. Sci. 271, 1625-1631. https://doi.org/10.1098/rspb.2004.2778

Lorenzen, K., 2016. Toward a new paradigm for growth modeling in fisheries stock assessments: Embracing plasticity and its consequences. Fish. Res. 180, 4-22. https://doi.org/10.1016/j.fishres.2016.01.006

Lorenzen, K., Enberg, K., 2002. Density-dependent growth as a key mechanism in the regulation of fish populations: evidence from among-population comparisons. Proc. R. Soc. Lond. B Biol. Sci. 269, 49-54. https://doi.org/10.1098/rspb.2001.1853

Mahe, K., Delpech, J.-P., Carpentier, A., 2007. Synthèse bibliographique des principales espèces de Manche orientale et du golfe de Gascogne.

Mollet, F.M., Engelhard, G.H., Vainikka, A., Laugen, A.T., Rijnsdorp, A.D., Ernande, B., 2013. Spatial variation in growth, maturation schedules and reproductive investment of female sole Solea solea in the Northeast Atlantic. J. Sea Res. 84, 109-121. https://doi.org/10.1016/j.seares.2012.12.005 
Petitgas, P., Rijnsdorp, A.D., Dickey-Collas, M., Engelhard, G.H., Peck, M.A., Pinnegar, J.K., Drinkwater, K., Huret, M., Nash, R.D.M., 2013. Impacts of climate change on the complex life cycles of fish. Fish. Oceanogr. 22, 121-139. https://doi.org/10.1111/fog.12010

Petitgas, P., Secor, D.H., McQuinn, I., Huse, G., Lo, N., 2010. Stock collapses and their recovery: mechanisms that establish and maintain life-cycle closure in space and time. ICES J. Mar. Sci. 67, 1841-1848. https://doi.org/10.1093/icesjms/fsq082

Pinheiro, J.C., Bates, D.M., 2000. Mixed-effects models in S and S-PLUS. Springer, New York.

Pita, A., Casey, J., Hawkins, S.J., Villarreal, M.R., Gutiérrez, M.-J., Cabral, H., Carocci, F., Abaunza, P., Pascual, S., Presa, P., 2016. Conceptual and practical advances in fish stock delineation.

Fish. Res.

173 , 185-193. https://doi.org/10.1016/j.fishres.2015.10.029

Quince, C., Abrams, P.A., Shuter, B.J., Lester, N.P., 2008. Biphasic growth in fish I: Theoretical foundations. J. Theor. Biol. 254, 197-206. https://doi.org/10.1016/j.jtbi.2008.05.029

Reiss, H., Hoarau, G., Dickey-Collas, M., Wolff, W.J., 2009. Genetic population structure of marine fish: mismatch between biological and fisheries management units. Fish Fish. 10, 361-395. https://doi.org/10.1111/j.1467-2979.2008.00324.x

Ricker, W.E., 1981. Changes in the average size and average age of Pacific salmon. Can. J. Fish. Aquat. Sci. 38, 1636-1656. https://doi.org/10.1139/f81-213

Rijnsdorp, A.D., Van Beek, F.A., 1991. Changes in growth of plaice Pleuronectes platessa L. and sole Solea solea (L.) in the North Sea. Neth. J. Sea Res. 27, 441-457. https://doi.org/10.1016/0077-7579(91)90045-3 
673 Rindorf, A., Wright, P.J., Jensen, H., Maar, M., 2016. Spatial differences in growth of lesser 674 sandeel in the North Sea. J. Exp. Mar. Biol. Ecol. 479, 9-19. 675 https://doi.org/10.1016/j.jembe.2016.02.007

676 Riou, P., 2001. Contribution respective de différentes nourriceries côtières aux

677

678

679

680

681

682

683

684

685

686

687

688

689

690

691

692

693

694 populations adultes de sole et de plie: étude par couplage de modèles linéaires généralisés avec un système d'information géographique. Aquat. Living Resour. 14, 125-135. https://doi.org/10.1016/S0990-7440(01)01110-X

Rochette, S., Huret, M., Rivot, E., Le Pape, O., 2012. Coupling hydrodynamic and individual-based models to simulate long-term larval supply to coastal nursery areas: Modelling larval supply to coastal nurseries. Fish. Oceanogr. 21, 229-242. https://doi.org/10.1111/j.1365-2419.2012.00621.x

Schnute, J., 1981. A Versatile Growth Model with Statistically Stable Parameters. Can. J. Fish. Aquat. Sci. 38, 1128-1140. https://doi.org/10.1139/f81-153

Secor, D.H., 2015. Migration ecology of marine fishes. Johns Hopkins University Press, Baltimore.

Sequeira, V., Neves, A., Paiva, R.B., Lima, J.P. de, Vieira, A.R., Gordo, L.S., 2012. Life history parameters as possible discriminators of bluemouth Helicolenus dactylopterus (Delaroche, 1809) populations in Portuguese waters. Fish. Res. 125-126, 69-76. https://doi.org/10.1016/j.fishres.2012.02.009

Sinclair, A.F., Swain, D.P., Hanson, J.M., 2002. Disentangling the effects of size-selective mortality, density, and temperature on length-at-age. Can. J. Fish. Aquat. Sci. 59, 372-382. https://doi.org/10.1139/f02-014 
695

696

697

698

699

700

701

702

703

704

705

706

707

708

709

710

711

712

713

714

715

716

717

Swain, D.P., Sinclair, A.F., Mark Hanson, J., 2007. Evolutionary response to size-selective mortality in an exploited fish population. Proc. R. Soc. B Biol. Sci. 274, 1015-1022. https://doi.org/10.1098/rspb.2006.0275

Tuck, G.N., Possingham, H.P., 1994. Optimal harvesting strategies for a metapopulation. Bull. Math. Biol. 56, 107-127. https://doi.org/10.1016/S0092-8240(05)80207-1

Von Bertalanffy, L., 1938. A quantitative theory of organic growth (inquiries on growth laws II). Human Biol. 10, 181-213.

Waples, R.S., Gaggiotti, O., 2006. What is a population? An empirical evaluation of some genetic methods for identifying the number of gene pools and their degree of connectivity: WHAT IS A POPULATION? Mol. Ecol. 15, 1419-1439. https://doi.org/10.1111/j.1365-294X.2006.02890.x

Weatherley, A.H., 1990. Approaches to Understanding Fish Growth. Trans. Am. Fish. Soc. 119 ,

$662-672$.

https://doi.org/10.1577/15488659(1990)119<0662:ATUFG>2.3.CO;2

Wheeler, A.C., 1978. Key to the fishes of northern Europe: a guide to the identification of more than 350 species. F. Warne, London.

Ying, Y., Chen, Y., Lin, L., Gao, T., Quinn, T., 2011. Risks of ignoring fish population spatial structure in fisheries management. Can. J. Fish. Aquat. Sci. 68, 2101-2120. https://doi.org/10.1139/f2011-116

Zemeckis, D.R., Martins, D., Kerr, L.A., Cadrin, S.X., 2014. Stock identification of Atlantic cod (Gadus morhua) in US waters: an interdisciplinary approach. ICES J. Mar. Sci. 71, 1490-1506. https://doi.org/10.1093/icesjms/fsu032 
Table 1

\begin{tabular}{|c|c|c|c|c|c|c|c|}
\hline & \multicolumn{2}{|r|}{ Data effect } & \multicolumn{5}{|c|}{ Growth comparison between subareas } \\
\hline & \multicolumn{2}{|r|}{ Model 1} & \multicolumn{2}{|c|}{ Model 2} & \multicolumn{3}{|c|}{ Model 3} \\
\hline $\begin{array}{l}\text { Data } \\
\text { Period }\end{array}$ & \multicolumn{2}{|c|}{$\begin{array}{c}\text { BTS + Commercial } \\
\text { Q 3 - SW NE }\end{array}$} & \multicolumn{2}{|c|}{$\begin{array}{c}\text { BTS data } \\
\text { Q 3-All areas }\end{array}$} & \multicolumn{3}{|c|}{$\begin{array}{c}\text { Commercial } \\
\text { All quarters - SW NE }\end{array}$} \\
\hline \multirow{4}{*}{$\begin{array}{l}\text { Effects included in full models } \\
\qquad \mathrm{K} \\
\mathrm{L}_{\infty} \\
\mathrm{L} 2\end{array}$} & Sex & data $\mathrm{x}$ subarea & Sex & Subarea & Sex & Subarea & Quarter \\
\hline & v & v & v & v & $\mathbf{v}$ & SW, NE & v \\
\hline & $\sqrt{ }$ & $\sqrt{ }$ & $\mathbf{v}$ & $\sqrt{ }$ & $\sqrt{ }$ & SW, NE & Not tested \\
\hline & $\sqrt{ }$ & $\sqrt{ }$ & $\sqrt{ }$ & $\sqrt{ }$ & $\sqrt{ }$ & SW, NE & $\sqrt{ }$ \\
\hline
\end{tabular}


Table 2

\begin{tabular}{|c|c|c|c|c|c|c|}
\hline & \multirow{2}{*}{\multicolumn{2}{|c|}{ Male }} & \multirow{2}{*}{\multicolumn{2}{|c|}{ Female }} \\
\hline & & & & & & \\
\hline $\begin{array}{c}\text { Growth } \\
\text { Parameters }\end{array}$ & Subarea & $\begin{array}{c}\text { Sampling } \\
\text { type }\end{array}$ & Value & $\begin{array}{l}\text { \% difference } \\
\text { (ref BTS in the } \\
\text { same area) }\end{array}$ & Value & $\begin{array}{c}\text { \% difference } \\
\text { (ref BTS in the } \\
\text { same area) }\end{array}$ \\
\hline \multirow{4}{*}{$\mathbf{K}$} & $\mathrm{NE}$ & BTS & 0.40 & & 0.33 & \\
\hline & NE & COM & 0.28 & -30 & 0.21 & -36 \\
\hline & SW & BTS & 0.39 & & 0.32 & \\
\hline & SW & COM & 0.41 & +4 & 0.33 & +4 \\
\hline \multirow{4}{*}{$\mathbf{L}_{\infty}$} & $\mathrm{NE}$ & BTS & 284 & & 352 & \\
\hline & NE & COM & 330 & +16 & 399 & +13 \\
\hline & SW & BTS & 317 & & 385 & \\
\hline & SW & COM & 336 & +6 & 404 & +5 \\
\hline \multirow{4}{*}{$L_{2}$} & $\mathrm{NE}$ & BTS & 207 & & 224 & \\
\hline & NE & COM & 239 & +15 & 255 & +14 \\
\hline & SW & BTS & 218 & & 234 & \\
\hline & SW & COM & 238 & +9 & 254 & +9 \\
\hline
\end{tabular}


Table 3

\begin{tabular}{|ccccccc|}
\cline { 3 - 7 } \multicolumn{1}{c}{} & \multicolumn{2}{c}{ Male } & \multicolumn{2}{c|}{ Female } \\
\hline $\begin{array}{c}\text { Growth } \\
\text { Parameters }\end{array}$ & Subarea & $\begin{array}{c}\text { Data } \\
\text { source }\end{array}$ & Value & $\begin{array}{c}\text { \% difference } \\
\text { (ref SW subarea) }\end{array}$ & Value & $\begin{array}{c}\text { \% difference } \\
\text { (ref SW subarea) }\end{array}$ \\
\hline \multirow{2}{*}{ K } & SW & BTS & 0,40 & & 0,31 & \\
& NE & BTS & 0,41 & $+2 \%$ & 0,32 & $+2 \%$ \\
& UK & BTS & 0,46 & $+16 \%$ & 0,37 & $+16 \%$ \\
\hline \multirow{2}{*}{$\mathbf{L}_{\infty}$} & SW & BTS & 316 & & 386 & \\
& NE & BTS & 283 & $-10 \%$ & 353 & $-9 \%$ \\
\hline \multirow{2}{*}{$\mathbf{L}_{\mathbf{2}}$} & UK & BTS & 293 & $-7 \%$ & 363 & $-6 \%$ \\
\hline & SW & BTS & 217 & & 234 & \\
& NE & BTS & 207 & $-5 \%$ & 224 & $-4 \%$ \\
\hline
\end{tabular}


Table 4

\begin{tabular}{|c|c|c|c|c|c|c|}
\hline & \multirow{2}{*}{\multicolumn{2}{|c|}{ Male }} & \multirow{2}{*}{\multicolumn{2}{|c|}{ Female }} \\
\hline & & & & & & \\
\hline $\begin{array}{c}\text { Growth } \\
\text { Parameters }\end{array}$ & Subarea & Quarter & Value & $\begin{array}{l}\text { \% difference } \\
\text { (ref NE subarea) }\end{array}$ & Value & $\begin{array}{c}\% \text { difference } \\
\text { (ref NE subarea) }\end{array}$ \\
\hline \multirow{4}{*}{ K } & $\mathrm{NE} / \mathrm{SW}$ & 1 & 0.20 & & 0.20 & \\
\hline & NE/SW & 2 & 0.26 & & 0.26 & \\
\hline & NE/SW & 3 & 0.26 & & 0.26 & \\
\hline & NE/SW & 4 & 0.20 & & 0.20 & \\
\hline \multirow{2}{*}{$L_{\infty}$} & $\mathrm{NE}$ & $1 / 2 / 3 / 4$ & 310 & & 386 & \\
\hline & SW & $1 / 2 / 3 / 4$ & 352 & +14 & 428 & +11 \\
\hline \multirow{4}{*}{$L_{2}$} & NE/SW & 1 & 243 & & 253 & \\
\hline & NE/SW & 2 & 220 & & 230 & \\
\hline & NE/SW & 3 & 244 & & 254 & \\
\hline & NE/SW & 4 & 258 & & 267 & \\
\hline
\end{tabular}




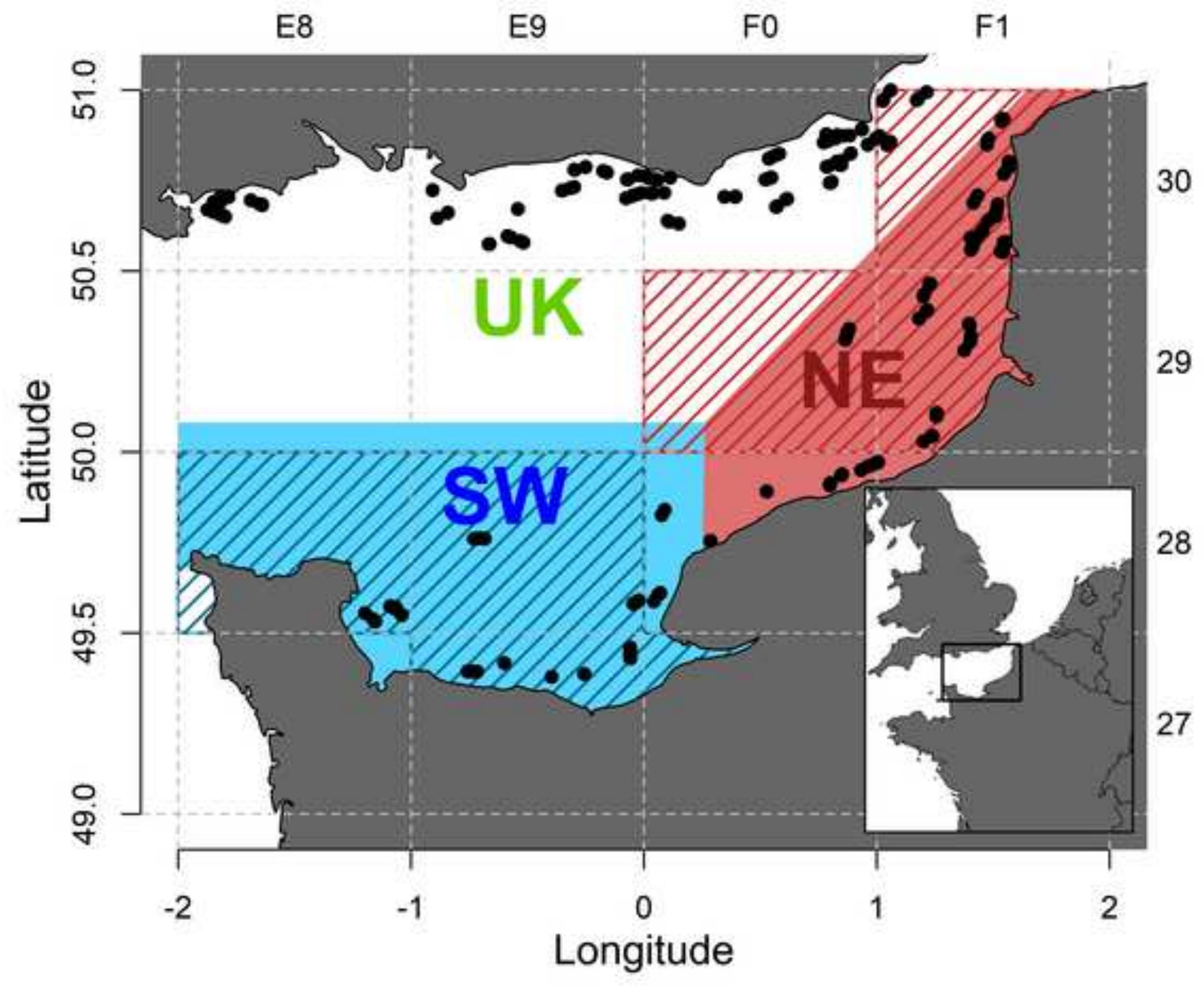



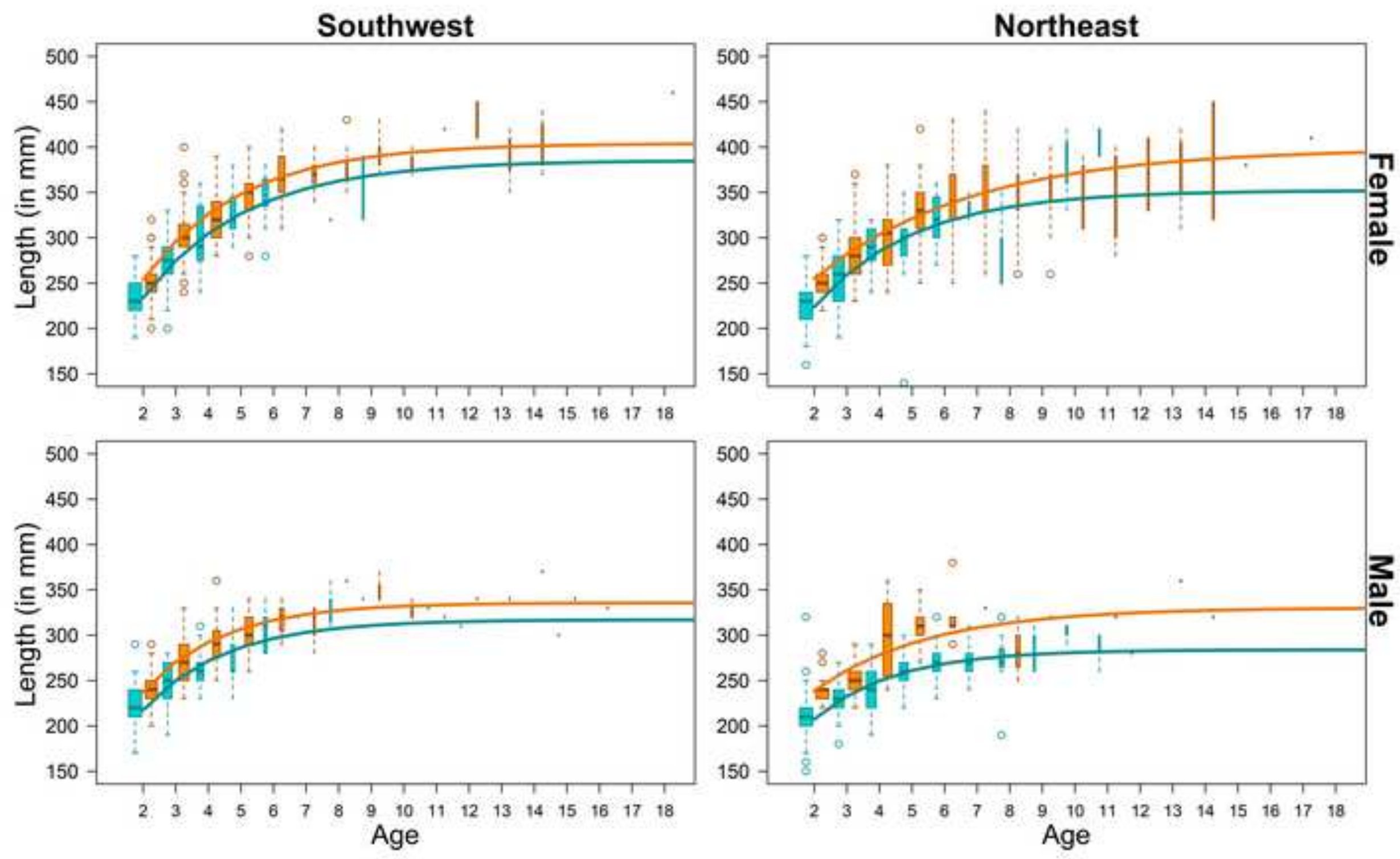

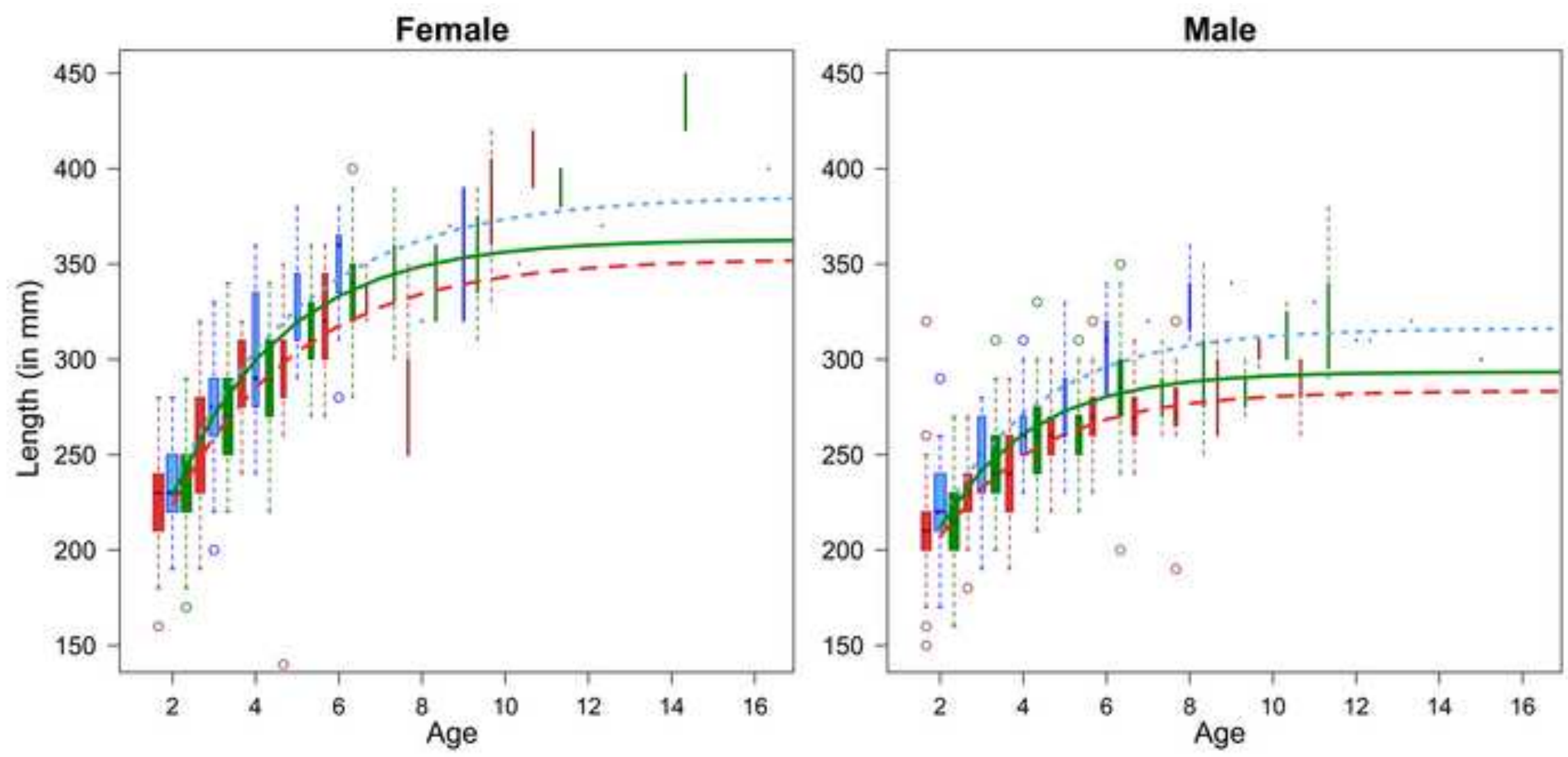
a.

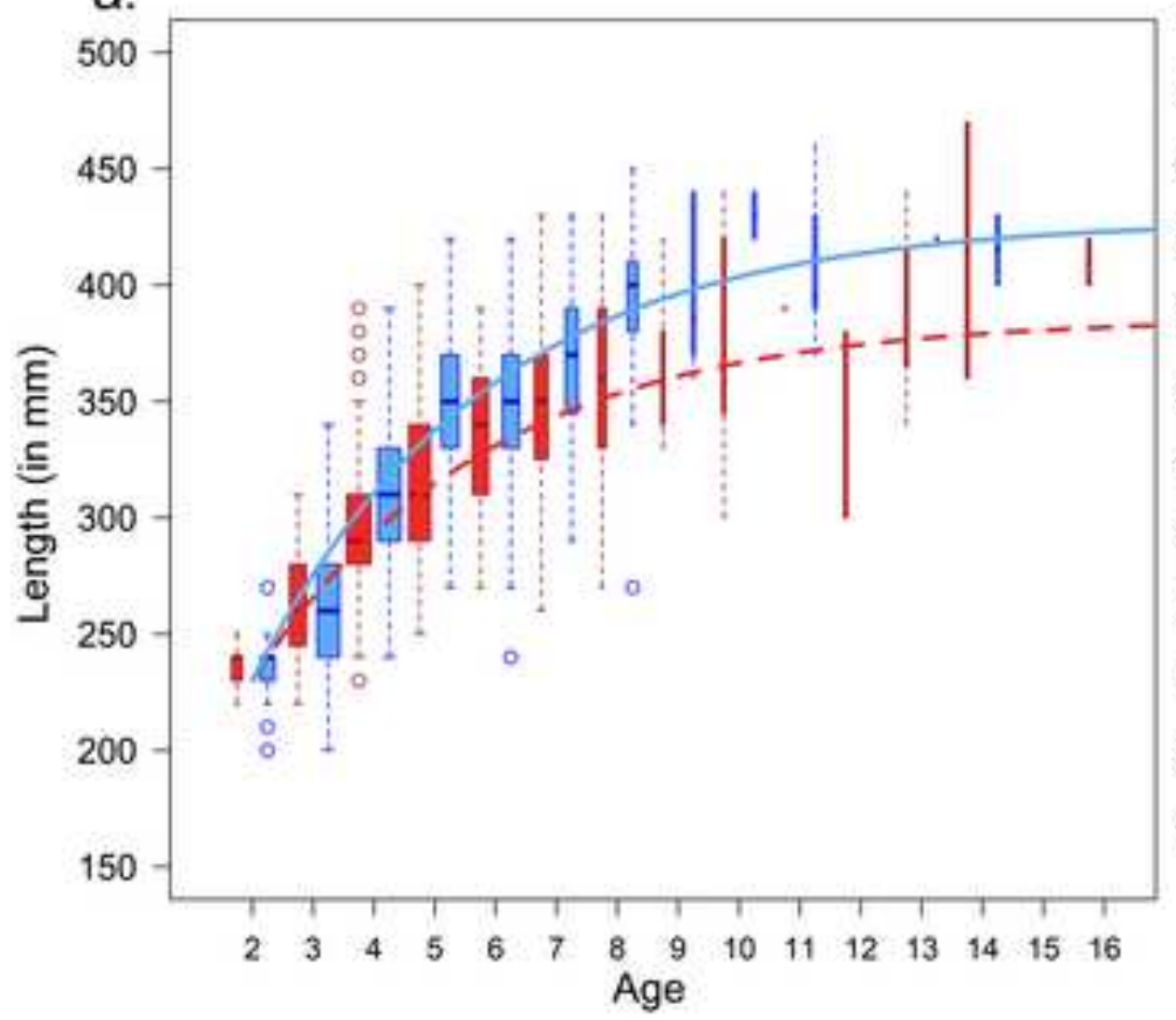

b.

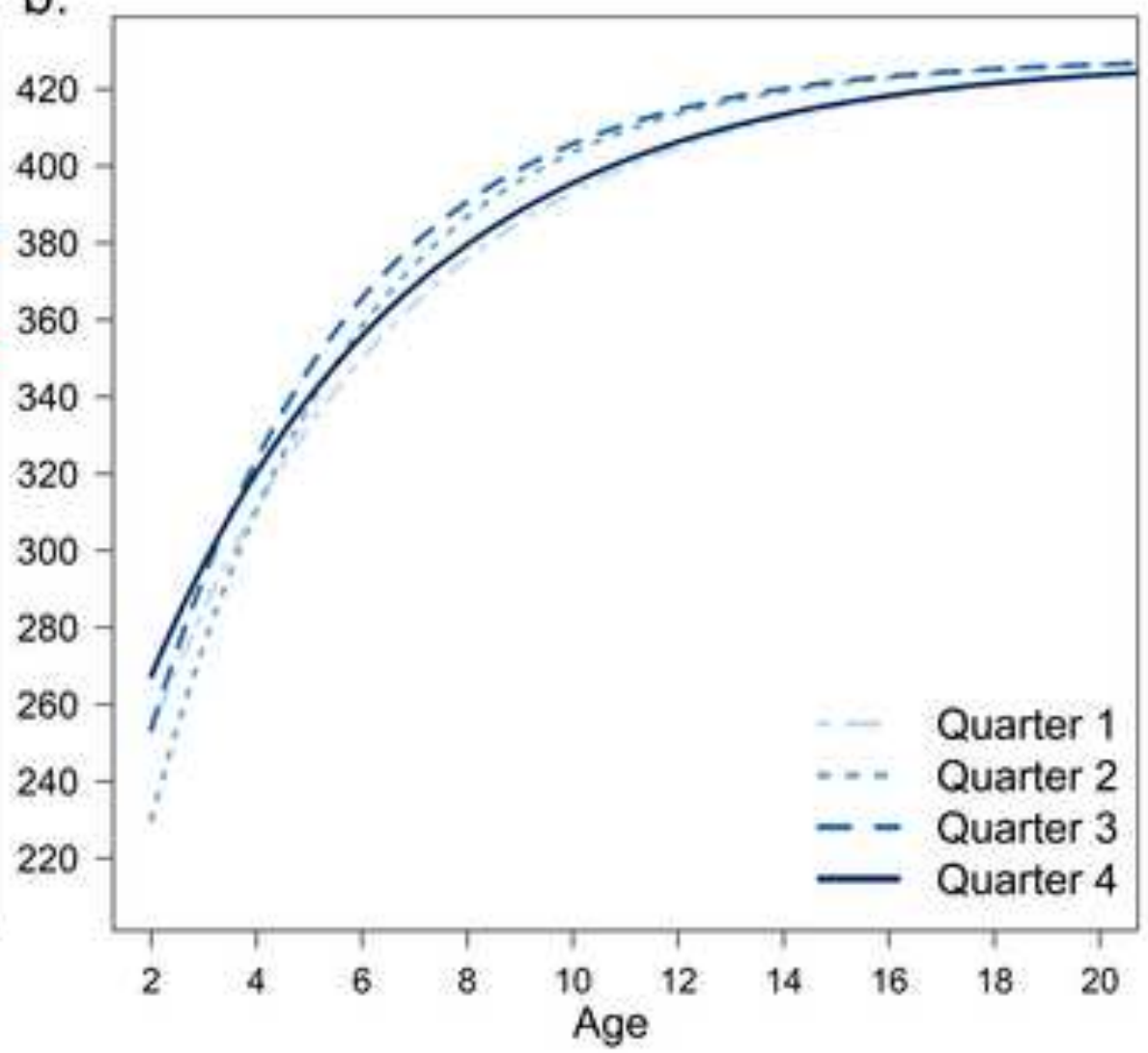




\section{Figure captions :}

Figure 1: The three subareas of the Eastern English Channel as proposed in (Archambault et al., 2015; Rochette et al., 2012) (UK: United Kingdom, NE: Northeast, SW: Southwest). The points represent haul positions of the UK-BTS (UK Beam Trawl Survey). The two coloured areas SW and NE in represent the subareas with French commercial sampling and the crosshatching ICES (International Council for the Exploration of the Sea) statistical rectangles were assigned to the Northeast and Southwest subareas respectively. Top and right axes correspond to the ICES statistical rectangle coordinates.

Figure 2: Von Bertalanffy growth curves for the Northeast and Southwest subareas of the Eastern English Channel for each data source, UK-BTS (UK Beam Trawl Survey) (dashed line in blue) and French commercial fisheries (solid line in orange). The curves separate female and male and were plotted from growth parameters computed from the model fitted with the two data sources. The boxplots represent the data distribution at each age, their widths are proportional to the number of data at each age and for each data source and the dots are the outliers at each age.

Figure 3: Von Bertalanffy growth curves for Northeast (dashed line in red), Southwest (dotted line in blue) and UK (solid line in green) subareas of the Eastern English Channel separating female and male, plotted from growth parameters computed from model fitted with scientific survey. The boxplots represent the data distribution at each age, their widths are proportional to the number of data at each age and in each subarea and the dots are the outliers at each age. 
Figure 4 : Von Bertalanffy growth curves plotted from growth parameters computed from model fitted with commercial fisheries: a. for Northeast (dashed line in red) and Southwest (solid line in blue) subareas for females during the quarter 2. b. for each quarter for females in the SW subareas. The boxplots represent the data distribution at each age, their widths are proportional to the number of data at each age and in each subarea and the dots are the outliers at each age. 

Supplementary material for on-line publication only
Click here to download Supplementary material for o

Click here to download Supplementary material for on-line publication only: supplementary_materials-rev3.docx 